\title{
Deletion Pattern of the STS Gene in X-linked Ichthyosis in a Mexican Population
}

\author{
Ana Luisa Jimenez Vaca, ${ }^{1}$ Margarita Valdes-Flores, ${ }^{2}$ Maria del Refugio Rivera-Vega, ${ }^{1}$ Luz María \\ González-Huerta, ${ }^{1}$ Susana Helen Kofman-Alfaro, ${ }^{1}$ and Sergio Alberto Cuevas-Covarrubias ${ }^{1}$ \\ ${ }^{1}$ Servicio de Genetica, Hospital General de Mexico, Facultad de Medicina, UNAM \\ ${ }^{2}$ Servicio de Genetica, Instituto Nacional de Ortopedia, Mexico D.F., MX \\ Accepted [add date]
}

\begin{abstract}
Background: X-linked ichthyosis (XLI) is an inherited disorder due to steroid sulfatase deficiency (STS). Most XLI patients $(>90 \%)$ have complete deletion of the STS gene and flanking sequences. The presence of low copy number repeats (G1.3 and CRI-S232) on either side of the STS gene seems to play a role in the high frequency of these interstitial deletions. In the present study, we analyzed 80 Mexican patients with XLI and complete deletion of the STS gene. Materials and Methods: STS activity was measured in the leukocytes using $7-\left[{ }^{3} \mathrm{H}\right]$-dehydroepiandrosterone sulfate as a substrate. Amplification of the regions telomeric-DXS89, DXS996, DXS1139, DXS1130, 5' STS, 3' STS, DXS1131, DXS1133, DXS237, DXS1132, DXF22S1, DXS278, DXS1134centromeric was performed through PCR.

Results: No STS activity was detected in the XLI patients (0.00 pmoles/mg protein/h). We observed 3 different

patterns of deletion. The first two groups included 25 and 32 patients, respectively, in which homologous sequences were involved. These subjects showed the 5' STS deletion at the sequence DXS1139, corresponding to the probe CRI-S232A2. The group of 32 patients presented the 3' STS rupture site at the sequence DXF22S I (probe G1.3) and the remaining 25 patients had the 3' STS breakpoint at the sequence DXS278 (probe CRI-S232B2). The third group included 23 patients with the breakpoints at several regions on either side of the STS gene. No implication of the homologous sequences were observed in this group.

Conclusion: These data indicate that more complex mechanisms, apart from homologous recombination, are occurring in the genesis of the breakpoints of the STS gene of XLI Mexican patients.
\end{abstract}

\section{Introduction}

$\mathrm{X}$-linked ichthyosis (XLI) is an inherited metabolism disorder resulting from steroid sulfatase (STS) deficiency (1). XLI is characterized by dark, adhesive and regular scales of skin. STS enzyme presents ubiquitous distribution and is capable of hydrolyzing steroid sulfates $(2,3)$. The STS gene spans more than $160 \mathrm{~kb}$ and is located on Xp22.3, close to the pseudoautosomal region $(4,5)$. Most XLI patients present large deletions of the STS gene and flanking sequences (6-12). The anonymous human genome clone CRI-S232 flanking the STS gene is composed of VNTRs and unique sequences. It has been suggested that the pattern of deletions observed in XLI patients is due to the presence of these low copy number repeats generating homologous recombination (13).

Previous reports in several geographic areas indicate that there are no racial or ethnic differences in the deletion pattern of the STS gene in XLI patients $(8,9,11,12)$. As there are no studies about the extent of the STS gene deletion and flanking markers in

Send correspondence and reprint requests to: Sergio Cuevas Covarrubias, Servicio de Genética, Hospital General de México, 148 Col. Doctores C.P. 06726, México D.F., MX. Phone: (525) 576-2841, fax: (525) 576-3541,

e-mail: sergioa@servidor.unam.mx
Mexican patients with XLI, the aim of the present study was to investigate the deletion pattern in 80 unrelated XLI patients.

\section{Material and Methods Patients}

Sample included 80 unrelated cases referred as having ichthyosis to the Genetic Department of the General Hospital of Mexico. Forty-eight subjects corresponded to sporadic cases while 32 patients were familial cases. They were informed about the characteristics of the study and they agreed to participate. The protocol was evaluated and approved by the Ethics Committee of the General Hospital.

\section{STS Assay}

STS activity was determined in leukocytes of the XLI patients as follows: $10 \mathrm{ml}$ of blood was obtained with a heparinized syringe. The leukocyte pellet was obtained through centrifugation and washed three times with $0.9 \% \mathrm{NaCl}$. STS assay was performed in the leukocyte pellet, which was homogenized in chilled 0.014 M Tris (hydroxymethyl-aminomethane buffer) with a polytron in two cycles of $20 \mathrm{~s}$ and $10 \mathrm{~s}$, respectively. $7-\left[{ }^{3} \mathrm{H}\right]-$ dehydroepiandrosterone sulfate $(16.3 \mathrm{Ci}$ per mmol, NEN, Boston, Mass.) was used as enzyme substrate. 
Table 1. Primers and condition-PCR analysis of flanking regions of the STS gene

\begin{tabular}{|c|c|c|c|}
\hline Locus & Primer Sequence & Annealing $\left({ }^{\circ} \mathbf{C}\right)$ & (bp) \\
\hline DXS89 & $\begin{array}{l}\text { F CGT TCT CAA CAA TAG ATC ACG } \\
\text { R ACT TAC ATT GGC AAT GCA TCC }\end{array}$ & 50 & 166 \\
\hline DXS996 & $\begin{array}{l}\text { F AAA TTC TTG CCT AGG CCA CTC TAG G } \\
\text { R ACG TTG TTC TGG ATC GTA TGC TAG G }\end{array}$ & 62 & $153-171$ \\
\hline DXS1139 & $\begin{array}{l}\text { F GCT TGG ATC AGG GCT GGA ATT AG } \\
\text { R TTA AAC AAG GGC CAT TCT GCA AG }\end{array}$ & 60 & 500 \\
\hline DXS1130 & $\begin{array}{l}\text { F TGT CTC AAC CGT CAA GTC AC } \\
\text { R CTT GTC TTT GAA GAT GCT CCC }\end{array}$ & 60 & 367 \\
\hline $5^{\prime}$ GEN STS & $\begin{array}{l}\text { F GGC CTA GAA GAA GGT TGA AGG TCC C } \\
\text { R AAG AGG TTG GAT GAG ATG GGC ATA C }\end{array}$ & 60 & 292 \\
\hline 3' GEN STS & $\begin{array}{l}\text { F GAA ATC CTC AAA GTC ATG CAG GAA G } \\
\text { R CCT CCA GTT GAG TAG CTG TTG AGC T }\end{array}$ & 60 & 363 \\
\hline DXS1131 + & $\begin{array}{l}\text { F CCA AAC TGC CAC TGG TTG AG } \\
\text { R CCG TGA TCT CTG ATG AAC CG }\end{array}$ & 58 & 170 \\
\hline DXS1133 & $\begin{array}{l}\text { F TGG TAG AAT ACA CTG CAG GTG TGC } \\
\text { R CAG CTT GTT AAG TGC TGT CTA TCC }\end{array}$ & 60 & 260 \\
\hline DXS237 & $\begin{array}{l}\text { F CAT GTG AGG AAT ACA GGA GCG AA } \\
\text { R GCC AAC TCA GCT AAT GAC TGT AG }\end{array}$ & 55 & 400 \\
\hline DXS1132 & $\begin{array}{l}\text { F TGC TAC AAG CAT TTC AGA GG } \\
\text { R CAA GCT CTG ACA TGT GAC TTC }\end{array}$ & 55 & 152 \\
\hline DXF22S I & $\begin{array}{l}\text { F ATC CAC TCC CCA TCT TAC CTT TCC C } \\
\text { R CAA ATA GAC CCC TTC TTG TCT GGG }\end{array}$ & 62 & 262 \\
\hline DXS278 & $\begin{array}{l}\text { F CCT TGA GTC TTT GTT CTG GAA CCC } \\
\text { R CTA CGT GGT TGA ATG CCT GGA CTC }\end{array}$ & 55 & 210 \\
\hline DXS1134 & $\begin{array}{l}\text { F TGA GTA TGT GCT TTG AGC TAG GGT C } \\
\text { R CTG CGA ACA ATT CTT TTA GTT CCT C }\end{array}$ & 50 & 400 \\
\hline
\end{tabular}

$+1 \%$ de DMSO (final concentration)

Conditions are: DNA $500 \mathrm{ng}$, primers $0.4 \mu \mathrm{M}$, dNTP's $0.08 \mathrm{mM}, \mathrm{MgCl}_{2} 1.5 \mathrm{mM}$, buffer $1 \mathrm{x}$, Taq Pol $1.5 \mathrm{U}$, vol $50 \mu \mathrm{L}$. Initial

denaturalized $2 \mathrm{~min}$ at $94^{\circ} \mathrm{C} ; 30$ cycles of: 1 min at $94^{\circ} \mathrm{C}$; 1 min of annealing; 1 min at $72^{\circ} \mathrm{C}$ and finally 5 min at $72^{\circ} \mathrm{C}$.

Assay conditions were $\mathrm{pH} 7.0$ at $37^{\circ} \mathrm{C}$ for $1 \mathrm{~h}$ in a final volume of $250 \mu \mathrm{l}$ of $0.014 \mathrm{M}$ Tris buffer. The product of hydrolysis was recovered with benzene (Merck, analytical grade, Germany) and read in a scintillation spectrometer (14). Each assay was performed twice with a normal male control included.

\section{DNA Analysis}

DNA extraction was performed as follows: $3 \mathrm{ml}$ of blood were extracted with EDTA syringe and mixed with $3 \mathrm{ml}$ of TTS buffer containing $10 \mathrm{mM}$ Tris, $1 \%$ triton X100 and $300 \mathrm{mM}$ sucrose (pH 7.6). After centrifugation for $6 \mathrm{~min}$ at $3000 \mathrm{rpm}$, supernatant was discarded and the leukocyte pellet was recovered. Then, the leukocyte pellet was mixed with $1 \mathrm{ml}$ of TTS buffer and centrifuged for $2 \mathrm{~min}$ at $12,000 \mathrm{rpm}$, this last step was repeated twice. Leukocyte pellet was resuspended for $2 \mathrm{~min}$ in $570 \mu \mathrm{l}$ of $5 \mathrm{mM} \mathrm{NaCl}$, then $30 \mu \mathrm{l}$ of $10 \%$ of SDS were added and vigorously homogenized. After $10 \mathrm{~min}$, the sample was vortexed with $200 \mu \mathrm{l}$ of saturated $\mathrm{NaCl}$ for $10 \mathrm{~min}$. The viscous mixture was centrifuged for $15 \mathrm{~min}$ at $12,000 \mathrm{~g}$ at $4^{\circ} \mathrm{C}$. Supernatant with the DNA was transferred, precipitated with cold ethanol, dried and redissolved in water. The STS gene was analyzed by polymerase chain reaction, PCR. The conditions and primers to amplify sequences telomeric-DXS89-DXS996-DXS1139DXS1130-5'STS-3'STS-DXS1131-DXS1133, DXS237DXS1132-DXF22S1-DXS278-DXS1134-centromeric of the STS gene are shown in Table 1 (15-17). All procedures were repeated two times.

\section{Results}

All patients had undetectable levels of STS activity (0.00 pmoles $/ \mathrm{mg}$ protein/h). Initial PCR analysis showed no amplification of 5' and 3' ends of the STS gene in all patients. PCR analyses of the flanking markers are summarized in Table 2. Thirty-two XLI patients $(40 \%)$ had the deletion pattern involving regions DXS1139 and DXF22S1. These regions have homologous sequences and represent one of the most 
Table 2. Breakpoints of the 80 XLI patients with complete deletion of the STS gene

\begin{tabular}{|c|c|c|c|c|c|c|c|c|c|c|c|c|c|}
\hline XLI Patients & $\begin{array}{c}\text { DXS } \\
89\end{array}$ & $\begin{array}{c}\text { DXS } \\
996\end{array}$ & $\begin{array}{l}\text { DXS } \\
1139\end{array}$ & $\begin{array}{l}\text { DXS } \\
1130\end{array}$ & STS $5^{\prime}$ & STS $3^{\prime}$ & $\begin{array}{l}\text { DXS } \\
1131\end{array}$ & $\begin{array}{l}\text { DXS } \\
1133\end{array}$ & $\begin{array}{c}\text { DXS } \\
237\end{array}$ & $\begin{array}{l}\text { DXS } \\
1132\end{array}$ & $\begin{array}{l}\text { DXF } \\
22 S 1\end{array}$ & $\begin{array}{c}\text { DXS } \\
278\end{array}$ & $\begin{array}{l}\text { DXS } \\
1134\end{array}$ \\
\hline & & & + & + & - & - & + & + & & & & & \\
\hline & & & + & + & - & - & + & + & & & & & \\
\hline & & & + & + & - & - & - & + & + & & & & \\
\hline & & & + & + & - & - & - & + & + & & & & \\
\hline & & & + & + & - & - & - & + & + & & & & \\
\hline & & & + & + & - & - & - & - & + & + & & & \\
\hline & & & + & + & - & - & - & - & - & + & + & & \\
\hline & & & + & + & - & - & - & - & - & - & - & + & + \\
\hline & & + & + & - & - & - & - & + & + & & & & \\
\hline & & + & + & - & - & - & - & + & + & & & & \\
\hline & & + & + & - & - & - & - & - & - & + & + & & \\
\hline \multirow[t]{12}{*}{$29 \% n=23$} & & + & + & - & - & - & - & - & - & - & + & + & \\
\hline & & + & + & - & - & - & - & - & - & - & - & + & + \\
\hline & & + & + & - & - & - & - & - & - & - & - & + & + \\
\hline & & + & + & - & - & - & - & - & - & - & - & + & + \\
\hline & & + & + & - & - & - & - & - & - & - & - & - & + \\
\hline & + & + & - & - & - & - & - & + & + & & & & \\
\hline & + & + & - & - & - & - & - & + & + & & & & \\
\hline & + & + & - & - & - & - & - & + & + & & & & \\
\hline & + & + & - & - & - & - & - & + & + & & & & \\
\hline & + & + & - & - & - & - & - & - & + & + & & & \\
\hline & + & + & - & - & - & - & - & - & - & + & + & & \\
\hline & + & + & - & - & - & - & - & - & - & + & + & & \\
\hline $40 \% \mathrm{n}=32$ & + & + & - & - & - & - & - & - & - & - & - & + & + \\
\hline $31 \% n=25$ & + & + & - & - & - & - & - & - & - & - & - & - & + \\
\hline \multicolumn{14}{|c|}{$\begin{array}{l}\text { [shaded] }=\text { deletion } \\
+=\text { normal amplification } \\
-=\text { no amplification }\end{array}$} \\
\hline
\end{tabular}

common deletion patterns reported in the literature $(11,12,19)$. In 25 XLI patients the breakpoints lied between loci DXS1139 and DXS278. These regions also have homologous sequences and have been involved in the breakpoints of a large number of XLI patients (22). Twenty-three cases (29\%) harbored heterogeneous rupture sites (Fig. 1). The breakpoints in these patients lied between the following loci: 2 patients: $5^{\prime}$ end-3'end of the STS gene; 3 patients: 5'end of the STS gene-DXS1131; 1 patient: 5'end of the STS geneDXS1133; 1 patient: 5'end of the STS gene-DXS237; 1 patient: 5'end of the STS gene-DXS22S1; 2 patients: DXS1130-DXS1131; 1 patient: DXS1130-DXS237; 1 patient: DXS1130- DXS1132; 3 patients: DXS1130DXF22S1; 1 patient: DXS1130-DXS278; 4 patients: DXS1139-DXS1131; 1 patient: DXS1139-DXS1133 and 2 patients: DXS1139-DXS237.

\section{Discussion}

About $90 \%$ of XLI patients present large deletions of the STS gene and flanking sequences. G1.3 and
CRI-S232 are interspersed on the $\mathrm{X}$ chromosome short arm flanking the steroid sulfatase locus $(18,19)$. The presence of these low copy number repeats on either side of the STS gene, promoting unequal crossing over, seems to play a role in the high frequency of these interstitial deletions. CRI-S232 is present in the $\mathrm{X}$ chromosome with a high degree of polymorphism while its presence in the $\mathrm{Y}$ chromosome is non-polymorphic. CRI-S232 is divided into 4 regions $(\mathrm{a}-\mathrm{d})$ by various restriction enzymes. The regions $b+c$ contain tandem repetitive sequences, designated RU2 and RU1, respectively. RU1 is composed by heterogeneous repeating units $30 \mathrm{bp}$ long while RU2 contains repeating unit 4 bp long with a low level of intra-repeat sequence variation (13). Previous studies indicate that most XLI patients have entire STS deletions caused by recombination between the locus DXS1139 and the loci DXSF22S1 or DXS278. These loci contain homologous sequences and it is thought that this recombination may be due to the homology of these loci and to the presence of the VNTR sequences of the RU2 

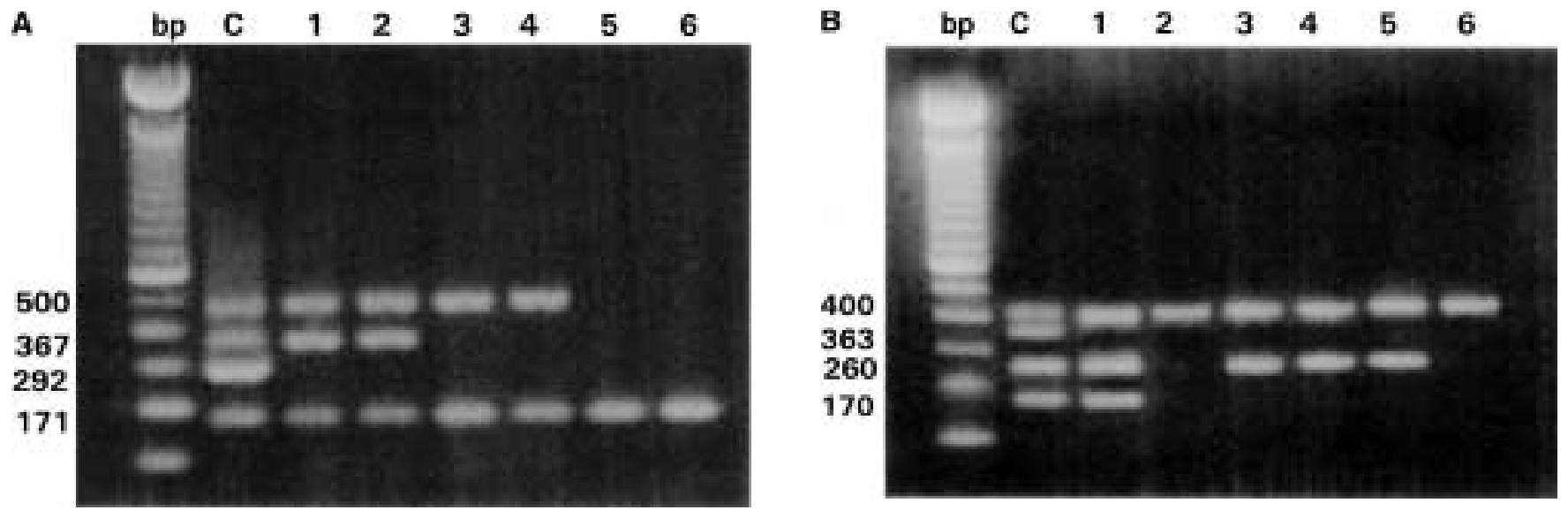

Fig. 1. PCR analysis of XLI patients with heterogeneous breakpoints. (A) Regions correspond from telomeric to centromeric to DXS996 (153-171 bp); DXS1139 (500 bp), DXS1130 (367 bp) and 5' STS (292 bp). Lines 1-6 show XLI patients. Line 1 and 2 show no amplification of region 5' STS, line 3 and 4 show no amplification of regions DXS1130 and 5' STS and lines 5 and 6 show no amplification of regions DXS1139, DXS1130 and 5' STS. C = Normal control. (B) Regions correspond from telomeric to centromeric to 3' STS (363 bp); DXS1131 (170 bp), DXS1133 (260 bp) and DXS237 (400). Lines 1-6 show the same XLI patients of the Fig. 1A. Line 1 shows no amplification of region 3' STS, line 2 shows no amplification of regions 3' STS, DXS1131 and DXS1133; lines 3, 4 and 5 show no amplification of regions $3^{\prime}$ STS and DXS1131 and line 6 shows no amplification of regions 3' STS, DXS1131 and DXS1133. $C=$ Normal control.

elements. The possible recombinogenic roll of some VNTR sequences has been previously reported $(20,21)$.

In the present study, we analyzed a sample of 80 XLI patients with entire deletion of the STS gene and flanking sequences. We classified our patients in three groups according to their deletion pattern. Homologous sequences were involved in the first two groups. The first group of 32 subjects $(40 \%)$ showed a deletion that included the loci DXS1139 and DXF22S1. Previous studies reported the implication of these loci in the rupture sites of XLI patients, although they harbored a very different percentage $(>80 \%)(11,12,19)$. In the second group of 25 patients $(31 \%)$, the rupture sites lie in the regions DXS1139 and DXS278. These breakpoints were also reported by Yen et al., in approximately $88 \%$ of their patients (22). It is important to state that we observed in these two groups rupture sites at the 3' flanking sequence of the STS gene at different loci, DXS22S1 and DXS278. The fact that these loci are involved at a similar percentage rate could be attributed to the presence of different polymorphisms in the regions DXS22S1 and DXS278 in our population. Further analysis will be required to discard this hypothesis.

On the other hand, we had a third group of 21 subjects with heterogeneous breakpoints that excluded these homologous sequences. In this group, homologous recombination was not responsible for generating these interstitial deletions of the STS gene and flanking sequences. Although heterogeneous breakpoints have been observed in previous reports, the number of patients has been too small for comparison with our third group. We do not know the mechanism that generates these deletions, but our data indicate that the presence of homologous loci or VNTR sequences is not the only mechanism playing a role in the high frequency of these interstitial deletions in Mexican patients. More refined studies will be necessary to clarify these findings.

In conclusion, we report three different deletion patterns in XLI patients in Mexican population. In two groups the sequences DXS1139 and DXSF22S 1 or DXS278 were involved while the third group presented a heterogeneous deletion pattern. These data indicate that homologous recombination is present in most XLI patients in the Mexican population as previously reported for other ethnic groups. Nevertheless, a third group with a heterogeneous deletion pattern shows that probably other mechanisms, besides homologous recombination, are promoting the entire deletion of the STS gene and flanking sequences in XLI Mexican patients.

\section{References}

1. Shapiro LJ, Weiss R. (1978) X-linked ichthyosis due to steroid sulphatase deficiency. Lancet 14: 70-72.

2. Hobkirk R. (1985) Steroid sulfotransferases and steroid sulfate sulfatases: Characteristics and biological role. Can. J. Biochem. Cell Biol. 63: 1127-1144.

3. Dibbelt L, Kuss E. (1991) Human placental sterylsulfatase: Interaction of the isolated enzyme with substrates, products, transition-state analogues, amino-acid modifiers and anion transport inhibitors. Biol. Chem. Hoppe-Seyler 372(3): 173-185.

4. Yen PH, Marsh B, Allen E, et al. (1988) The human X-linked steroid sulfatase gene and a Y-encoded pseudogene: Evidence for an inversion of the $\mathrm{Y}$ chromosome during primate evolution. Cell 55: 1123-1135.

5. Muller C, Walhstrom J, Rogers H. (1981) Further evidence for assignment of steroid sulfatase X-linked ichthyosis locus to the telomere of Xp. Hum. Genet. 58: 446.

6. Bonifas JM, Morley BJ, Oakey RE, et al. (1987) Cloning of cDNA for steroid sulfatase: Frequent occurrence of gene 
deletions in patients with recessive $\mathrm{X}$-chromosome-linked ichthyosis. Proc. Natl. Acad. Sci. USA 84: 9248-9251.

7. Yen PH, Allen E, Marsh B, et al. (1987) Cloning and expression of steroid sulfatase cDNA and the frequent occurrence of deletions in STS deficiency: Implications for X-Y interchange. Cell 49: 443-454.

8. Shapiro LJ, Yen P, Pomerantz D, et al. (1989) Molecular studies of deletions at the human steroid sulfatase locus. Proc. Natl. Acad. Sci. USA 86: 8477-8481.

9. Ballabio A, Carrozzo R, Parenti G, et al. (1989) Molecular heterogeneity of steroid sulfatase deficiency: A multicenter study on 7 unrelated patients at DNA and protein levels. Genomics 4: 36-40.

10. Cuevas-Covarrubias S, Kofman-Alfaro S, Maya G, et al. (1997) X-linked ichthyosis in Mexico: High frequency of deletions in the steroid sulfatase encoding gene. Am. J. Med. Genet. 72: 415-416.

11. Saeki H, Kuwata S, Nakagawa H, et al. (1998) Deletion pattern of steroid sulphatase gene in Japanese patients with $\mathrm{X}$ linked ichthyosis. Br. J. Dermatol. 139: 96-89.

12. Aviram-Goldring A, Goldman B, Netanelov-Shapira I, et al. (2000) Deletion patterns of the STS gene and flanking sequences in Israeli $\mathrm{X}$-linked ichthyosis patients and carriers: Analysis by polymerase chain reaction and fluorescence in situ hybridization techniques. Int. J. Dermatol. 39: 182-187.

13. Xiao-Miao L, Yen P, Shapiro LJ. (1992) Characterization of a low copy repetitive element S232 involved in the generation of frequent deletions of the distal short arm of the human Xchromosome. Nucl. Acids. Res. 20: 1117-1122.

14. Cuevas-Covarrubias S, Juarez-Oropeza M, Miranda-Zamora $R$, (1993) Comparative analysis of human steroid sulfatase activity in pre and postpubertal males and females. Biochem. Mol. Biol. Inter. 30: 691-695.

15. Ballabio A, Ranier JE, Chamberlain JS, et al. (1990) Screening for steroid sulfatase (STS) gene deletions by multiplex DNA amplification. Hum. Genet. 84: 571-572.

16. Schaefer L, Ferrero GB, Grillo A, et al. (1993) A high resolution deletion map of human chromosome Xp22. Nature Genet. 4: 272-279.

17. Valdes-Flores $M$, Kofman-Alfaro $\mathrm{SH}$, Jimenez Vaca $\mathrm{AL}$, Cuevas-Covarrubias SA. (2000) A novel partial deletion of exons 2-10 of the STS gene in recessive X-linked ichthyosis. J. Invest. Dermatol. 114: 591-593.

18. Knowlton RG, Nelson CA, Brown A, et al. (1989) An extremely polymorphic locus on the short arm of the human $X$ chromosome with homology to the long arm of the Y chromosome. Nucl. Acid Res. 17: 423-437.

19. Ballabio A, Bardoni B, Guioli S, et al. (1990) Two families of low-copy-number repeats are interspersed on Xp22.3: implications for the high frequency of deletions in this region. Genomics 8: 263-270.

20. Jarman AP, Wells RA. (1989) Hypervariable minisatellites: recombinators or innocent bystanders? Trends Genet. 5: 367371.

21. Wahls WP, Wallace LJ, Moore PD. (1990) Hypervariable minisatellite DNA is a hotspot for homologous recombination in human cells. Cell 60: 95-103.

22. Yen P, Xiao-Miao L, Siao-Ping T, et al. (1990) Frequent deletions of the human $X$ chromosome distal short arm result from recombination between low copy repetitive elements. Cell 51: 603-610. 